\title{
Effects of Glyceraldehyde on the Structural and Functional Properties of Sickle Erythrocytes
}

\author{
Alan M. Nigen and James M. Manning, The Rockefeller University, \\ New York 10021
}

\begin{abstract}
A B S T RACT The D- and L-isomers of glyceraldehyde are equally effective in the inhibition of SS erythrocyte sickling in vitro. The following compounds at a concentration of $20 \mathrm{mM}$ were ineffective in inhibiting sickling: glyceraldehyde-3-phosphate, D-erythrose, D-ribose, D-fructose, D-glucose, D-sucrose, dihydroxyacetone, and methylglyoxal. Glyceraldehyde does not reverse the sickling of cells in the deoxy state. The properties of purified hemoglobin after treatment with glyceraldehyde and of the hemoglobin isolated from treated cells are very similar; these results suggest that glyceraldehyde itself is the reactive species within the erythrocyte. Erythrocyte glutathione is decreased by treatment in vitro with the aldehyde.

Relatively high concentrations of glyceraldehyde $(50 \mathrm{mM})$ lead to a small amount $(3 \%)$ of crosslinking between hemoglobin monomers as well as to some cross-linking of erythrocyte membrane proteins. Lower concentrations of DL-glyceraldehyde (5-20 $\mathrm{mM}$ ), which reduce the sickling of erythrocytes in vitro, lead to proportionally less cross-linking of hemoglobin. Cells that have been treated with those concentrations of the aldehyde show little change in their osmotic fragility, exhibit improved filtration properties, and have a lowered viscosity.
\end{abstract}

\section{INTRODUCTION}

Recently, we reported that DL-glyceraldehyde inhibited the sickling of $\mathrm{S} / \mathrm{S}$ erythrocytes in vitro (1). This aldehyde reacts with hemoglobin $S$ to produce a significant increase in the minimum gelling concentration of the deoxygenerated protein with minimal effects on the oxygen equilibrium parameters. In those studies we surveyed only morphological changes in

\footnotetext{
Dr. Nigen's current address is University of Miami School of Medicine. Reprint requests can be addressed to Dr. Manning at The Rockefeller University.

Received for publication 21 July 1977 and in revised form 12 September 1977.
}

the treated erythrocytes. In the present communication we present further studies on the effects of glyceraldehyde on hemoglobin and on some structural and functional properties of the erythrocyte.

\section{METHODS}

Whole blood from patients homozygous for sickle cell anemia was collected into heparinized tubes by venipuncture and was used within $48 \mathrm{~h}$; informed consent was obtained in all cases. Crystalline DL-glyceraldehyde, sodium borohydride, dihydroxyacetone, methylglyoxal, glyceraldehyde-3-phosphate, D- and L-glyceraldehyde, and Dfructose were obtained from Sigma Chemical Co., St. Louis, Mo. D-Glucose was from J. T. Baker Chemical Co., Phillipsburg, N. J., D-ribose from Fluka, Basel, Switzerland, sucrose from Mallinckrodt Inc., St. Louis, Mo., and D-erythrose from P-L Biochemicals, Inc., Milwaukee, Wis. D- $\left[{ }^{14} \mathrm{C}\right] \mathrm{Glyc}-$ eraldehyde $(10.5 \mathrm{mCi} / \mathrm{mmol})$ was from New England Nuclear, Boston, Mass. All other chemicals were reagent grade.

In vitro sickling experiments. These experiments were carried out as described previously (1).

Physical measurements. Oxygen dissociation curves of whole cells and of isolated hemoglobin, and the minimum gelling concentration of isolated hemoglobin, were determined as described previously $(1,2)$. Viscosity measurements of whole cells were carried out at $37^{\circ} \mathrm{C}$ with a Harkness viscometer fitted with a $0.5-\mathrm{mm}$ bore capillary (Coulter Electronics, Inc., Hialeah, Fla.); the shear rate for the experiments was $>100 / \mathrm{s}$ (3). Before the measurement of viscosity, erythrocytes were resuspended in phosphatebuffered saline (PBS), ${ }^{1} \mathrm{pH} 7.4$ (4), to a hematocrit of $40 \%$. For measurement of the viscosity of deoxygenated samples, cells $(2.0 \mathrm{ml})$ were equilibrated with water-saturated nitrogen in a chamber at $37^{\circ} \mathrm{C}$ for $30 \mathrm{~min}$; a few grains of sodium dithionite were then added to ensure complete deoxygenation. After an additional $5 \mathrm{~min}$ of equilibration with nitrogen, the sample was transferred anaerobically to the viscometer. For measurement of the viscosity of oxygenated cells, equilibration was carried out at $37^{\circ} \mathrm{C}$ for $10 \mathrm{~min}$ before transfer to the viscometer. All values are reported as relative viscosity compared to water whose viscosity had been measured under the same conditions. Between four and five measurements were made with each $2.0-\mathrm{ml}$ sample and the values were averaged.

In experiments where the deformability of erythrocytes

${ }^{1}$ Abbreviations used in this paper: $\mathrm{Hb}$, hemoglobin; PBS, phosphate-buffered saline; SDS, sodium dodecyl sulfate. 
was measured by filtration through micropore filters, washed erythrocytes, either untreated or treated with glyceraldehyde, were resuspended at a concentration of $0.5 \%$ in PBS that contained $400 \mathrm{mg}$ of bovine serum albumin $/ 100 \mathrm{ml}$. For each determination, samples were first equilibrated with air or with a venous gas mixture $(90.4 \%$ $\mathrm{N}_{2}, 3.8 \% \mathrm{O}_{2}, 5.8 \% \mathrm{CO}_{2}$ ) for $30 \mathrm{~min}$ at $37^{\circ} \mathrm{C}$ with stirring. Deoxygenated samples were transferred by positive pressure from the equilibration vessel through Saran tubing into a filtration vessel (15-ml glass vessel; Millipore Corp., Bedford, Mass.) that was jacketed at $37^{\circ} \mathrm{C}$ and also flushed with a venous gas mixture. On top of the fritted glass filter holder was a polycarbonate filter (Nuclepore Corp., Pleasanton, Calif.) ( $25 \mathrm{~mm}$ in diameter with $5-\mu \mathrm{m}$ pores). A graduated cylinder was adapted for collection of the filtrate and for application of a partial vacuum of $9 \mathrm{~cm}$ of $\mathrm{Hg}$ by a water aspirator with an on-line regulator valve to attain the desired negative pressure. Filtration was initiated by opening a stopcock attached to a vacuum line and the time for filtration of all of the suspending medium was measured with a stopwatch. The filtered cells were then collected and centrifuged; the amount of lysis was determined by measurement at $540 \mathrm{~nm}$ of any hemoglobin in the supernatant solution and of the amount of hemoglobin in the packed erythrocytes.

Determinations of osmotic fragility were performed as described by Emerson et al. (5). Samples were adjusted to a hematocrit of $40 \%$ before addition of the sodium chloride solution.

Gel electrophoresis. Sodium dodecyl sulfate (SDS) polyacrylamide gel electrophoresis of isolated proteins was carried out as described by Weber and Osborn (6) with 7.5 or $10 \%$ cross-linked gels. The electrophoretic system used to study erythrocyte membrane proteins was similar to that described by Fairbanks et al. (7), except that $5 \%$ crosslinked gels were used. After staining with Coomassie Blue, the amount of protein in each band was measured at 600 $\mathrm{nm}$ on a Gilford 222 spectrophotometer (Gilford Instrument Laboratories Inc., Oberlin, Ohio) equipped with a model 2520 gel scanner.

Hemoglobin purification. Hemoglobin S from patients homozygous for sickle cell anemia was purified on a column $(2 \times 30 \mathrm{~cm})$ of DE-52 cellulose equilibrated with $0.05 \mathrm{M}$ Tris buffer, $\mathrm{pH} 8.5$; a linear gradient of $0.05 \mathrm{M}$ Tris, $\mathrm{pH} 8.3$ $(500 \mathrm{ml})$ and $0.05 \mathrm{M}$ Tris, pH $7.3(500 \mathrm{ml})$ was used to elute the protein (8). The column was operated at a flow rate of $45 \mathrm{ml} / \mathrm{h}$ at $4^{\circ} \mathrm{C}$.

Glutathione determination. The measurement of reduced glutathione was carried out on the amino acid analyzer. ${ }^{2}$

Incubation of erythrocytes with glyceraldehyde. For experiments in which cells treated with glyceraldehyde were to be studied, suspensions of oxygenated erythrocytes, washed with PBS, pH 7.4, and freed of buffy coat were adjusted to their original hematocrit and incubated with glyceraldehyde for $90 \mathrm{~min}$ at $37^{\circ} \mathrm{C}$. The cells were then washed three times with the buffered saline. For experiments with radioactive $\mathrm{D}\left[{ }^{14} \mathrm{C}\right]$ glyceraldehyde, the incubations were carried out in an identical fashion except that the solutions contained $9 \mu \mathrm{Ci} / \mathrm{ml}$ of the radioactive compound.

\section{RESULTS}

Effect of various compounds on erythrocyte sickling in vitro. A comparison of the antisickling properties

${ }^{2}$ In this procedure, glutathione is carbamylated with sodium cyanate to form S-carbamyl glutathione; the technique is analogous to the determination of cyanate as $S$ carbamyl cysteine (9). of the isomers of glyceraldehyde shown in Table I clearly indicates that the enantiomers of glyceraldehyde are equally effective antisickling agents in vitro. Dihydroxyacetone, the tautomer of glyceraldehyde, does not affect erythrocyte sickling. Glyceraldehyde3-phosphate, a product of glyceraldehyde metabolism within the erythrocyte (10), exhibits no effect upon sickling, perhaps because it does not cross the erythrocyte membrane.

Studies on a number of other related compounds showed that sugars of chain length longer than glyceraldehyde such as D-erythrose, D-ribose, D-fructose, and D-glucose, all of which occur predominantly in the hemiacetal form, have no effect upon sickling at a concentration of $20 \mathrm{mM}$. Sucrose, a nonreducing disaccharide, is also ineffective at this concentration. Methylglyoxal has been shown to be formed slowly from glyceraldehyde in solution (11), but treatment of erythrocytes with this compound resulted in cell lysis and oxidation of hemoglobin. Acetaldehyde had no effect upon erythrocyte sickling (data not shown).

To test whether glyceraldehyde could restore normal morphology to sickled cells in the deoxy state, erythrocytes were equilibrated for $30 \mathrm{~min}$ at $37^{\circ} \mathrm{C}$ with the venous gas mixture before anaerobic addition of glyceraldehyde and incubation for an additional 90 min. After fixation of the cells with formalin, the results shown in Table II were obtained. Clearly,

TABLE I

Effect of Sugars and Related Compounds on the Sickling of Erythrocytes

\begin{tabular}{lc}
\hline \multicolumn{1}{c}{ Compound } & $\begin{array}{c}\text { Cells with } \\
\text { normal morphology }\end{array}$ \\
\hline DL-Glyceraldehyde & $\%$ \\
D-Glyceraldehyde & 69 \\
L-Glyceraldehyde & 69 \\
Dihydroxyacetone & 72 \\
Glyceraldehyde 3-phosphate & 28 \\
D-Erythrose & 24 \\
D-Ribose & 25 \\
D-Fructose & 30 \\
D-Glucose & 20 \\
D-Sucrose & 26 \\
Methylglyoxal & 26 \\
No compound & Cells destroyed
\end{tabular}

Oxygenated erythrocytes in PBS, $\mathrm{pH} 7.4$, were incubated for $90 \mathrm{~min}$ at $37^{\circ} \mathrm{C}$ with the indicated compound at $20 \mathrm{mM}$ concentration. After deoxygenation with the venous gas mixture $\left(90.4 \% \mathrm{~N}_{2}, 3.8 \% \mathrm{O}_{2}, 5.8 \% \mathrm{CO}_{2}\right.$ ) for $30 \mathrm{~min}$, the cells were fixed with formalin. A sample not incubated with the venous gas mixture gave $79 \%$ normal cells. The percentage of normal cells was determined by two or three observers counting at least 500 cells with a phase contrast microscope at $\times 860$ magnification. 
TABLE II

Test for Reversal of Cell Sickling by DL-Glyceraldehyde

\begin{tabular}{ccc}
\hline & \multicolumn{2}{c}{ Cells with normal morphology } \\
\cline { 2 - 3 } Glyceraldehyde & Deoxy incubation* & Oxy incubation \\
\hline$m M$ & $\%$ & $\%$ \\
0 & 31 & 28 \\
10 & 23 & 50 \\
20 & 18 & - \\
\hline
\end{tabular}

* Erythrocytes suspended in PBS were deoxygenated with the venous gas mixture at $37^{\circ} \mathrm{C}$ for $30 \mathrm{~min}$. Glyceraldehyde was then added anaerobically and incubation was continued for an additional $90 \mathrm{~min}$.

$\$$ Experiment was carried out as described in Table I. A sample not incubated with the venous gas mixture gave $81 \%$ normal cells.

glyceraldehyde does not reverse sickling and, in fact, the degree of sickling appears to be somewhat increased.

Effect of glyceraldehyde on the physical properties of normal and sickle-cell hemoglobin. We have previously shown that increasing concentrations of glyceraldehyde lead to a small shift to the left in the oxygen dissociation curve of hemoglobin $(\mathrm{Hb}) \mathrm{S}$. As shown in Table III, glyceraldehyde affects the oxygen dissociation curve of $\mathbf{H b A}$ in erythrocytes to a similar extent.

To determine whether the observed changes in oxygen binding and minimum gelling concentration of $\mathrm{HbS}$ from erythrocytes treated with glyceraldehyde are due to modification by glyceraldehyde itself, or to a metabolic product of glyceraldehyde formed within the erythrocyte, we compared the properties of purified $\mathrm{HbS}$ that had been treated with glyceraldehyde to that of $\mathrm{HbS}$ isolated from cells that were treated with the compound; these results are summarized in Table IV. The extent of change in $P_{50}$,

TABLE III

Comparison of the Effect of Glyceraldehyde on the Oxygen Equilibrium of Normal and Sickle Cells

\begin{tabular}{ccc}
\hline Glyceraldehyde & $\begin{array}{c}\text { SS } \\
\text { erythrocytes }\end{array}$ & $\begin{array}{c}\text { AA } \\
\text { erythrocytes }\end{array}$ \\
\hline$m M$ & $P_{\mathrm{so}}$ & $P_{\mathrm{so}}$ \\
0 & 36.3 & 25.9 \\
20 & 32.4 & 20.9 \\
\hline
\end{tabular}

Cells $(0.1 \mathrm{ml})$ were suspended in $5 \mathrm{ml}$ PBS, $\mathrm{pH} 7.3$, at $37^{\circ} \mathrm{C}$ and the oxygen dissociation curves were determined as described previously (1). For treated cells, $20 \mathrm{mM}$ glyceraldehyde was used for $90 \mathrm{~min}$ at $37^{\circ} \mathrm{C}$. The data for SS erythrocytes have been published previously as log values (1). Fresh cells were used and the concentrations of 2,3-DPG were assumed to be normal.
TABLE IV

Comparison of the Properties of Purified Hemoglobin S after Treatment with Glyceraldehyde and of Hemoglobin S Isolated from Erythrocytes Treated with Glyceraldehyde

\begin{tabular}{lccc}
\hline \multicolumn{1}{c}{ Sample } & Log $\mathrm{P}_{\mathrm{so}^{*}}$ & $\begin{array}{c}\text { Hill } \\
\text { coefficient }\end{array}$ & $\begin{array}{c}\text { Minimum gelling } \\
\text { concentrationt }\end{array}$ \\
\hline & & & $\mathrm{g} / 100 \mathrm{ml}$ \\
Purified HbS & & & \\
$\quad$ Untreated & 0.70 & 3.2 & 23.9 \\
$\quad$ Treated & 0.56 & 1.9 & 28.3 \\
HbS from erythrocytes & & & \\
$\quad$ Untreated & 0.71 & 3.0 & 23.9 \\
$\quad$ Treated & 0.64 & 2.1 & 29.2 \\
\hline
\end{tabular}

* Oxygen saturation curves were carried out at $25^{\circ} \mathrm{C}$ in $0.05 \mathrm{M}$ Bis-Tris $0.1 \mathrm{M} \mathrm{Cl}^{-}, \mathrm{pH} 7.3$, with $50 \mu \mathrm{M}$ hemoglobin tetramer. Isolated $\mathrm{Hb}(1 \mathrm{mM})$ or intact cells resuspended to their original hematocrit (approximately $1 \mathrm{mM}$ in $\mathrm{Hb}$ ) were incubated with $20 \mathrm{mM}$ glyceraldehyde at $37^{\circ} \mathrm{C}$ for $90 \mathrm{~min}$. $\ddagger$ The minimum gelling concentration was determined at pH 7.2 at $25^{\circ} \mathrm{C}$ in $0.15 \mathrm{M}$ phosphate buffer (12).

Hill coefficient, and minimum gelling concentration are similar for the two hemoglobin samples. These results suggest that glyceraldehyde is the reactive species within the erythrocyte.

Incorporation of glyceraldehyde into blood components. Glyceraldehyde shows similar reactivity with erythrocyte proteins and plasma proteins (Table V) when consideration is given to the fact that the protein concentration within the erythrocyte is threefour times that of the plasma (13). Glyceraldehyde also reacts with membrane proteins as discussed below.

After reaction of erythrocytes with $20 \mathrm{mM}$ glyceraldehyde for $90 \mathrm{~min}$ at $37^{\circ} \mathrm{C}$, approximately 2.0 glycerollysine residues per $\mathrm{Hb}$ tetramer were found (1). Experiments with radioactive glyceraldehyde now indicate that an additional two groups of glyceraldehyde per molecule are incorporated into the protein. When the labeled hemoglobin was subjected to amino acid analysis after reduction with $\mathrm{NaBH}_{4}$ and acid hydrolysis, two major peaks of radioactivity were found, as determined with a scintillation flow cell attached

TABLE V

Distribution of $D-\left[{ }^{14} \mathrm{C}\right]$ Glyceraldehyde after Reaction with Whole Blood

\begin{tabular}{lc}
\hline \multicolumn{1}{c}{ Sample } & $\begin{array}{c}\text { Amount } \\
\text { incorporated }\end{array}$ \\
\hline & $\%$ \\
Erythrocyte lysate & 78 \\
Plasma proteins & 21 \\
Erythrocyte membrane & 1 \\
\hline
\end{tabular}


to the amino acid analyzer. One peak corresponded to the position of glycerollysine and the second component chromatographed in the void volume of both columns of the amino acid analyzer; no glycerolvaline was detected.

Since some aldehydes are known to result in crosslinking of proteins (14), we investigated the molecular weight of the hemoglobin after treatment of erythrocytes with glyceraldehyde. As shown in Fig. 1, hemoglobin that had been exposed to $50 \mathrm{mM}$ glyceraldehyde shows the presence of a dimeric component which has been estimated by spectrophotometric scanning of the gels to be about $3 \%$ of the hemoglobin monomer (lower band); the amount of dimer is proportionally less with the $20-\mathrm{mM}, 10-\mathrm{mM}$, and $5-\mathrm{mM}$ glyceraldehyde concentrations. When the hemoglobin samples were reduced with $\mathrm{NaBH}_{4}$, the relative amounts of hemoglobin dimer were unchanged. Application of a large amount of hemoglobin to the gel (not shown) reveals the presence of small amounts of trimeric and tetrameric components with the higher concentrations of glyceraldehyde. The light band present in the untreated hemoglobin sample probably represents carbonic anhydrase (mol wt 31,000).

Myoglobin, ribonuclease, and the $\alpha$-chain of hemoglobin, all monomeric proteins, do not appear to undergo cross-linking with glyceraldehyde under these experimental conditions (Fig. 2). Evidently, the

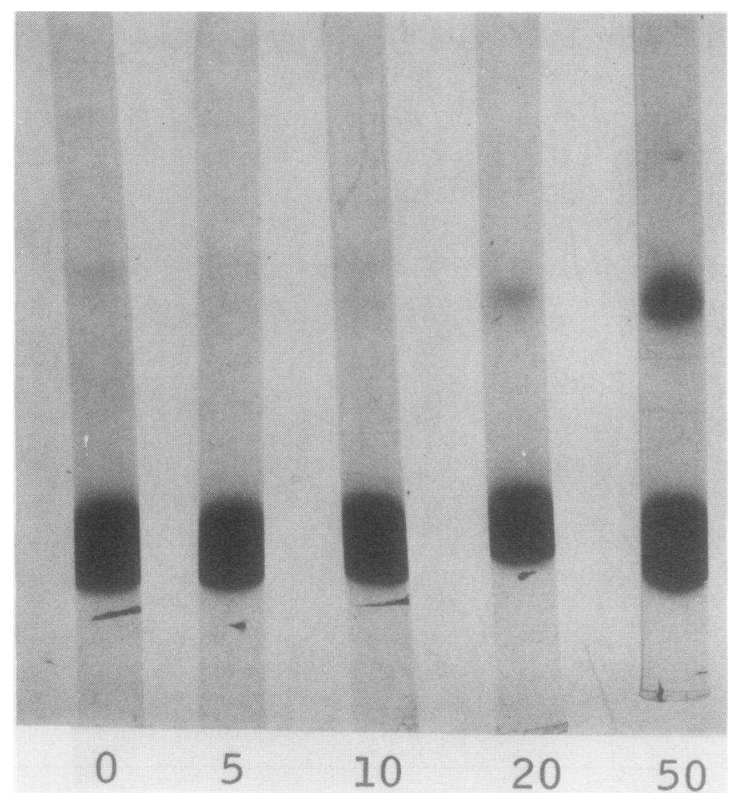

FIGURE 1 SDS gels of hemolysates from erythrocytes treated with DL-glyceraldehyde. Erythrocytes, suspended in PBS, pH 7.3, were treated with the indicated concentrations of glyceraldehyde for $90 \mathrm{~min}$ at $37^{\circ} \mathrm{C}$. After washing of the cells, lysis, and dialysis, $100 \mu \mathrm{g}$ of protein was electrophoresed in $10 \%$ cross-linked gels as described in Methods.

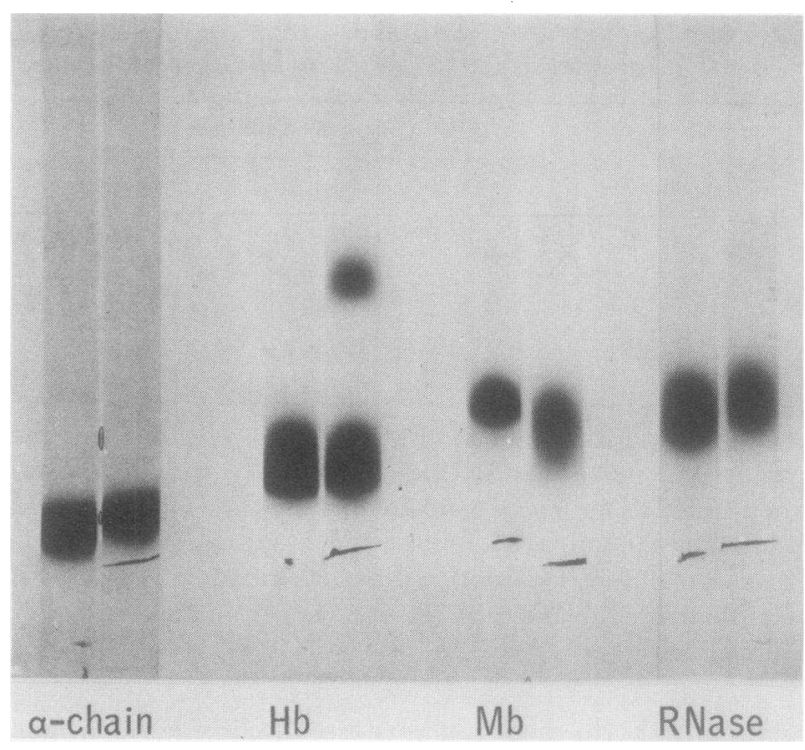

FIGURE 2 SDS gels of protein untreated and treated with glyceraldehyde. The proteins were suspended in PBS, pH 7.3, at a concentration of $2 \mathrm{mg} / \mathrm{ml}$ and were treated with $0.1 \mathrm{M}$ glyceraldehyde for $90 \mathrm{~min}$ at $37^{\circ} \mathrm{C}$. After exhaustive dialysis $100 \mu \mathrm{g}$ of protein was electrophoresed in $10 \%$ cross-linked gels as described in Methods.

proximity of subunits in the hemoglobin tetramer facilitates the cross-linking reaction.

The effect of glyceraldehyde on erythrocyte membrane proteins is shown in Fig. 3; the numbering system is that of Fairbanks et al. (7). The most obvious change is the formation of high molecular weight material at the top of the gels for the sample treated with $20 \mathrm{mM}$ glyceraldehyde. The presence of this new band taken together with loss of some material in bands 1 and 2.1 indicates some polymerization of spectrin. There are other changes in the gel profiles, but they do not appear to be the result of cross-linking. For example, band 6 represents glyceraldehyde-3-phosphate dehydrogenase, a protein that has been shown to be loosely associated with the erythrocyte membrane (15). This protein has been shown to dissociate from the membrane in the presence of metabolic intermediates such as NAD (15). Further investigation will be necessary to determine whether the activity of this enzyme or other enzymes in the erythrocyte membrane have been altered by treatment with glyceraldehyde. The heavy band near the bottom of the gels represents hemoglobin monomer which, at higher concentrations of the aldehyde, becomes increasingly difficult to wash free from the membrane; near the position of band 7 dimeric hemoglobin chains are also apparent with the high concentrations of glyceraldehyde.

Gels which have been electrophoresed in an identical fashion but stained with Schiff's reagent rather 


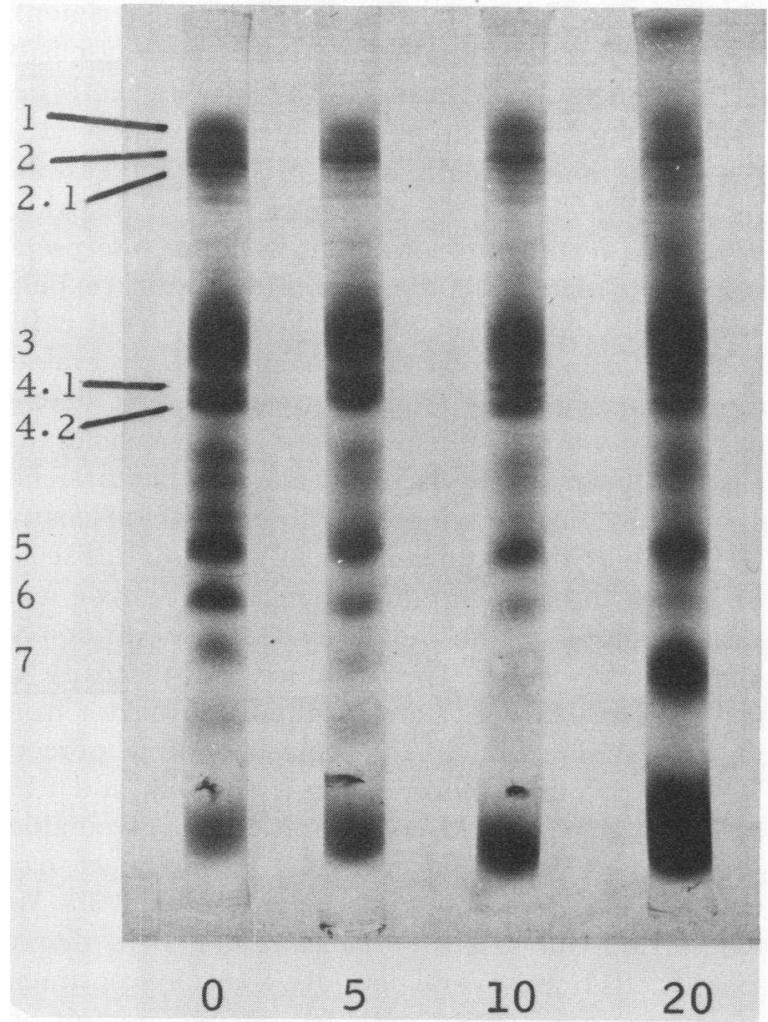

FIGURE 3 SDS gels of membrane proteins from erythrocytes treated with DL-glyceraldehyde. Erythrocytes were incubated as described in the legend of Fig. 1 and the membranes were isolated and electrophoresed $(100 \mu \mathrm{g})$ in $5 \%$ cross-linked gels as described by Fairbanks et al. (7).

than Coomassie Blue, show that the major glycoprotein of the erythrocyte membrane is unaffected by treatment with glyceraldehyde.

Since aldehydes are known to form adducts with -SH groups, we have investigated the possible interaction of glyceraldehyde with erythrocyte glutathione (Fig. 4). There is a marked reduction in the amounts of reduced glutathione in the presence of increasing concentrations of glyceraldehyde. In addition the adduct appears to be fairly stable since washing of the cells after treatment with glyceraldehyde but before determination of glutathione did not regenerate the reduced form of the metabolite.

Effect of glyceraldehyde on erythrocyte properties. The effects of glyceraldehyde upon the membrane proteins described above prompted an investigation of the physiological properties of the erythrocyte which might be impaired by any cross-linking in the membrane. Figs. 5 and 6 show the curves of osmotic fragility for sickle and normal cells, respectively, that had been treated with varying concentrations of the aldehyde. For sickle cells, there is a very slight decrease in osmotic fragility with increasing concentra-

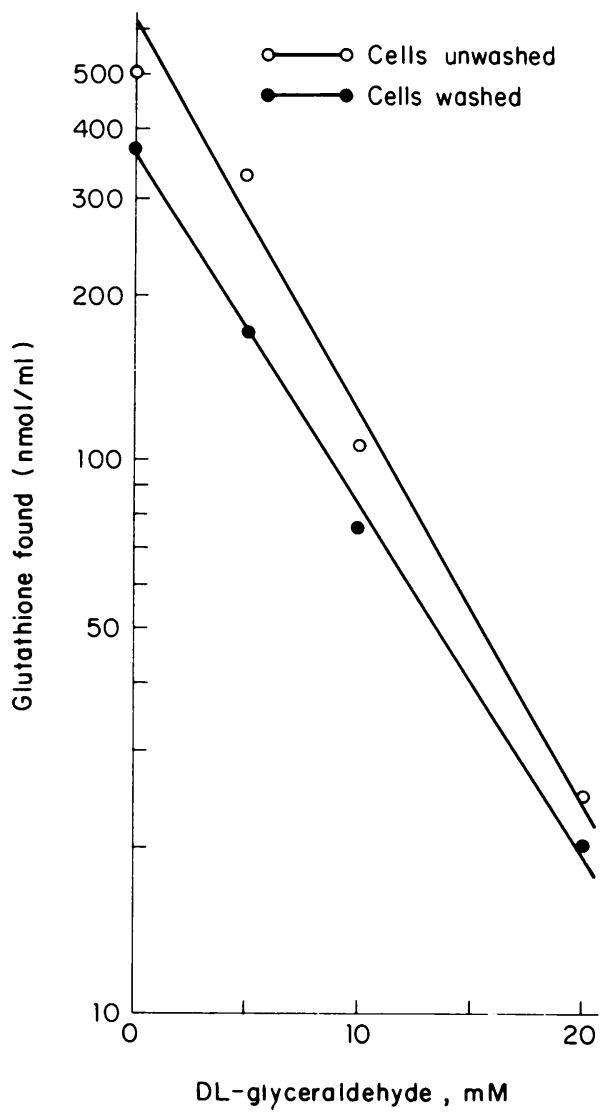

Figure 4 Determination of reduced glutathione after treatment of intact erythrocytes with DL-glyceraldehyde. Erythrocytes, suspended in PBS, pH 7.3, were incubated for $90 \mathrm{~min}$ at $37^{\circ} \mathrm{C}$ with the indicated concentrations of DLglyceraldehyde. Glutathione was determined as carbamyl glutathione, ${ }^{2}$ immediately after incubation with glyceraldehyde $(\mathrm{O}-\mathrm{O})$ and after washing of the cells three times with PBS (-

tions of the aldehyde. Thus, after treatment of cells with $20 \mathrm{mM}$ glyceraldehyde, the osmotic fragility curves fall within what would be considered the standard range for sickle cells $(16,17)$. For normal cells, a similar effect was observed. At high concentrations of the aldehyde $(>50 \mathrm{mM})$ it became difficult to lyse the cells.

The effect of glyceraldehyde on erythrocyte deformability and viscosity. At atmospheric pressure deoxygenated sickle erythrocytes did not pass through a 5- $\mu \mathrm{m}$ Nucleopore filter. After treatment with glyceraldehyde, some of the cells passed through the filter but clogging soon occurred and filtration ceased. Therefore, it was difficult to quantitate the effect of glyceraldehyde on erythrocyte deformability at atmospheric pressure. We elected to carry out these studies at negative pressures that would permit determination of the time for passage of all of the liquid in which the cells were suspended, whether or not all 


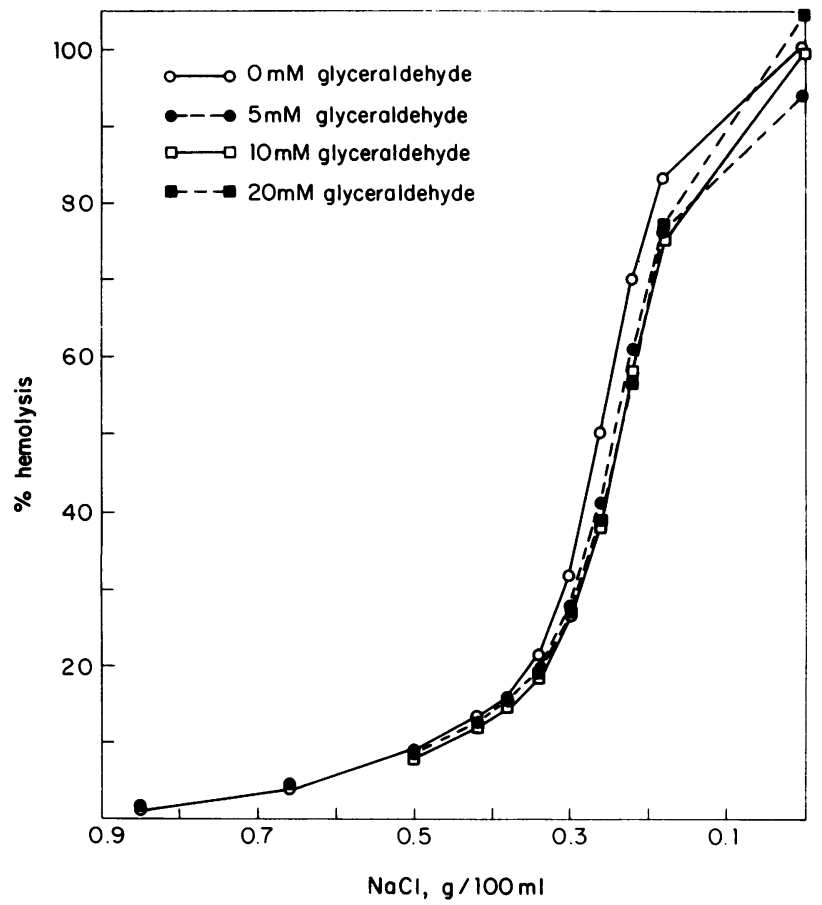

Figure 5 Effect of DL-glyceraldehyde on the osmotic fragility of SS erythrocytes. Erythrocytes were incubated for $90 \mathrm{~min}$ at $37^{\circ} \mathrm{C}$ with the indicated concentrations of glyceraldehyde and then washed three times with PBS. The hematocrits were adjusted to $40 \%$ and $0.1 \mathrm{ml}$ of the suspended cells were diluted into $1.0 \mathrm{ml}$ of the salt solution. After gentle mixing on a Vortex mixer (Scientific Industries, Inc., Bohemia, N. Y.) and centrifugation, the concentration of the supernates were determined with Drabkins reagent.

of the erythrocytes were filtered. A negative pressure of $9 \mathrm{~cm} \mathrm{Hg}$ was chosen where passage of the liquid was complete with a minimum of lysis of cells in the filtrate. As shown in Table VI, filtration of normal erythrocytes under these conditions was rapid, with very little cell lysis (3\%); oxygenated sickle cells were also rapidly filtered. Deoxygenated erythrocytes from Patient 1 were almost completely filtered and the time for filtration was reduced by about twothirds after treatment with glyceraldehyde; the percentage of lysed cells in this experiment was $13 \%$. The deoxygenated erythrocytes from Patient 2 were more difficult to filter; $84 \%$ of the untreated erythrocytes from Patient 2 were retained on the filter. Variability in the filtration rates of sickle erythrocytes from patient to patient has been reported (18). Treatment with glyceraldehyde resulted in passage of most of the cells through the filter. The amount of lysed cells in the filtrate of either treated or untreated erythrocytes (33\%) was greater for the erythrocytes from this patient probably because of the extended time of filtration.

The relative viscosity of cells treated with glyc- eraldehyde is shown in Fig. 7. These experiments were carried out at a high shear rate where viscosity measurements should reflect changes in cell deformability under certain physiological conditions (19). Oxygenated normal cells show a small increase in viscosity with increasing concentrations of the aldehyde; these results are consistent with the interpretations of the data from the osmotic fragility experiments described above. For oxygenated sickle cells, this increase in viscosity as a function of glyceraldehyde concentration is slightly greater. Upon deoxygenation of normal cells, there is only a small increase in the relative viscosity. Deoxygenated sickle cells show a marked increase in relative viscosity, which reflects the pathogenesis of sickle-cell disease (16). Increasing concentrations of glyceraldehyde lead to a decrease in the relative viscosity of deoxygenated sickle cells. The data for the viscosity of deoxy SS cells in Fig. 7 are for the erythrocytes from one patient for which the corresponding percent of cells with normal morphology is 39,55 , and $61 \%$ with 0,10 , and $20 \mathrm{mM}$ concentrations of glyceraldehyde, respectively. The relative viscosity of oxygenated cells from the same patient was 3.55 . We have carried out viscosity measurements on deoxygenated cells from several patients. In each experiment a decrease in viscosity with increasing amounts of glyceraldehyde was observed. However, both the

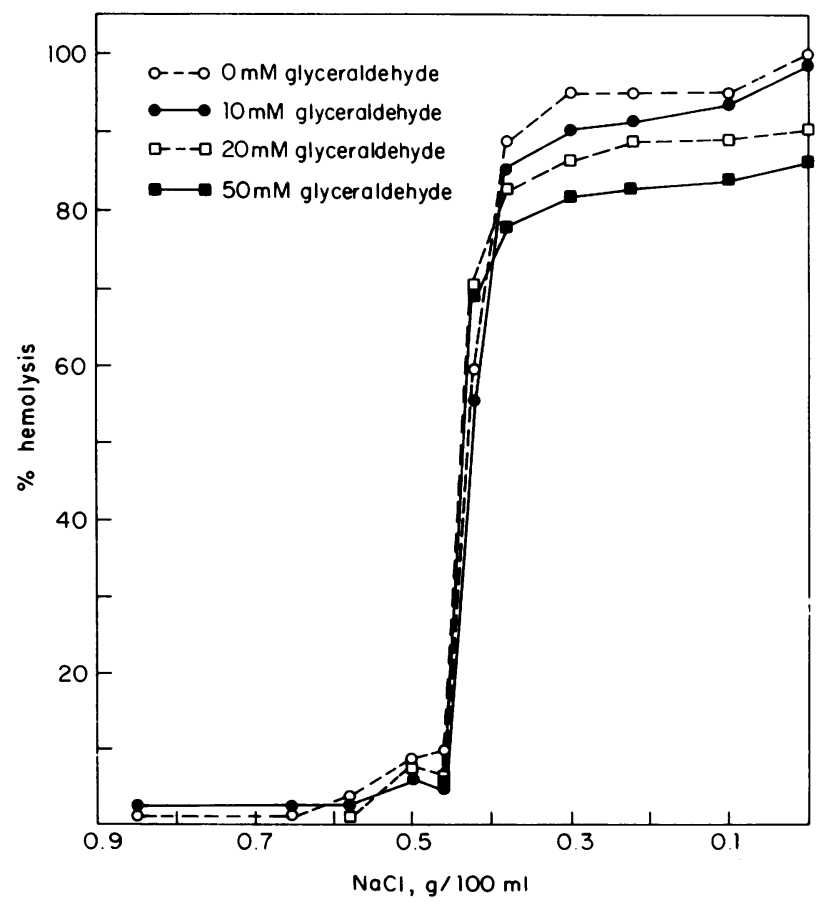

Figure 6 Effect of DL-glyceraldehyde on the osmotic fragility of AA erythrocytes. Experiments were carried out as described in the legend to Fig. 5. 
TABLE VI

Effect of Glyceraldehyde on the Filterability of Deoxygenated Erythrocytes

\begin{tabular}{cccccccc}
\hline & \multicolumn{4}{c}{ Cells filtered* } \\
\cline { 2 - 7 } Glyceraldehyde & $\begin{array}{c}\text { Normal } \\
\text { subject }\end{array}$ & Patient 1 & Patient 2 \\
\hline$m M$ & $\%$ & $s$ & $\%$ & $s$ & $\%$ & $s$ \\
0 & 100 & 3 & 85 & 85 & 16 & 385 \\
20 & 100 & 3 & 84 & 30 & 69 & 374 \\
\hline
\end{tabular}

* Average of two-three determinations, deviation $\pm 11 \%$.

absolute values and the extent of decrease by treatment with glyceraldehyde vary with the erythrocytes from patient to patient and, hence, the data were not averaged. Similar variability in the degree of morphological change for sickle-cell erythrocytes from different patients has been noted with both sodium cyanate (20) and with glyceraldehyde (1) during in vitro studies.

\section{DISCUSSION}

The selection of DL-glyceraldehyde for study as a potential antisickling agent was based upon observations on the specificity of aldehydes such as pyridoxal phosphate (21), pyridoxal sulfate (21), and glucose (22-24) for the $\mathrm{NH}_{2}$-terminal residues of hemoglobin and the increased solubility of deoxy $\mathrm{HbS}$ carbamylated at the $\mathrm{NH}_{2}$-terminal residues (2). However, although glyceraldehyde effectively inhibited the sickling of SS erythrocytes, the initial studies showed that reaction at the $\mathrm{NH}_{2}$-terminal residues was negligible but that lysine residues were a major site of reaction (1). We have now confirmed that observation in studies with $\mathrm{D}-\left[{ }^{14} \mathrm{C}\right]$ glyceraldehyde. The adduct(s) formed with hemoglobin and glyceraldehyde that are responsible for the inhibition of sickling are stable in physiological buffers by several criteria in vitro. Thus, washing of treated cells three times with PBS saline did not reverse the antisickling effect of glyceraldehyde. Furthermore, the electrophoretic mobility, the minimum gelling concentration, and the amounts of glycerollysine found upon acid hydrolysis of the treated hemoglobin were unchanged after several weeks at $4^{\circ} \mathrm{C}$. Reduction with sodium borohydride is only necessary for analytical purposes to provide glycerollysine residues which are stable to the conditions of acid hydrolysis (1). Amino acid analysis of the reduced and acid hydrolyzed protein modified with labeled glyceraldehyde shows two major peaks of radioactivity, neither of which corresponds to the elution position of glycerolvaline. One peak of radioactivity elutes in the position of glycerollysine and the other component(s) elutes in the position of free glyceraldehyde. Since unbound glyceraldehyde had been removed from the samples before acid hydrolysis, the latter peak is probably due to hydrolysis of an acid-labile adduct whose identification is presently under study.

The identical effects of the D- and L-isomers of glyceraldehyde on the morphology of sickle-cell erythrocytes indicates that it is simply the reactivity of the free aldehyde group rather than the stereochemistry of the compound that determines its antisickling effect. In addition, the morphological studies that were initially carried out with DL-glyceraldehyde can now be compared with confidence to the radioisotope experiments with labeled D-glyceraldehyde in the present study.

Among the sugars studied at a concentration of 20 $\mathrm{mM}$, glyceraldehyde is the most efficient antisickling agent in vitro. All of the longer chain sugars had no effect upon sickling, probably due to their much lower reactivity, since they occur predominantly in the ring conformation. Recently Abdella et al. (25)

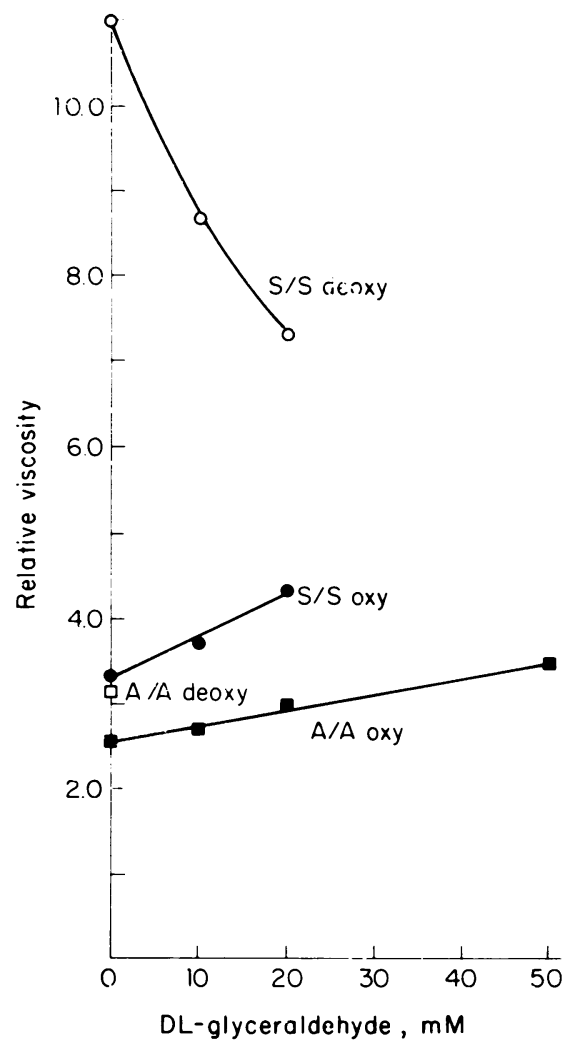

FIGURE 7 Relative viscosity of erythrocytes after incubation with DL-glyceraldehyde. Erythrocytes were incubated for 90 minutes at $37^{\circ} \mathrm{C}$ with DL-glyceraldehyde and then washed three times with PBS. The hematocrits were adjusted to $40 \%$ and the relative viscosity was determined at $37^{\circ} \mathrm{C}$ as described in Methods; average of four-five determinations, deviation $\pm 5 \%$. 
reported that glycosylation of isolated $\mathrm{HbS}$ by reducing sugars (i.e., glucose or galactose) increases the minimum gelling concentration of deoxy $\mathrm{HbS}$ but a concentration of about $300 \mathrm{mM}$ was used to achieve that effect in vitro.

We have begun to investigate possible deleterious effects of glyceraldehyde upon erythrocyte structure and function. For oxygenated normal and sickle erythrocytes the decrease in osmotic fragility and the increase in viscosity with increasing concentrations of glyceraldehyde are slight. For the experiments on viscosity, the measurements were carried out at a $40 \%$ hematocrit so that any small differences due to treatment with glyceraldehyde could be detected. However, since most sickle-cell anemia patients have hematocrits below $30 \%$, it would be expected that the differences observed would be even less at the lower hematocrit. The finding that the viscosity of deoxygenated SS erythrocytes decreases with increasing concentrations of glyceraldehyde is indicative of an improved deformability of the sickle erythrocyte and is consistent with the morphological findings on the greater percentage of normal cells after incubation with the aldehyde.

The loss of reduced glutathione after reaction with glyceraldehyde is consistent with the findings of van Heyningen (26). She observed a reduction in glutathione after treatment of lens extracts with glyceraldehyde and she obtained three separate products on thin layer chromatograms; these products were not identified. It will be important to determine whether the treated cell given the proper metabolites can regenerate its supply of glutathione.

Glyceraldehyde does not improve the morphology of cells already sickled. This finding could indicate that an amino acid residue whose reactivity with glyceraldehyde is essential for the antisickling effect may not be available for reaction within the deoxy HbS aggregate. Alternatively, the aldehyde may crosslink the membrane in the sickled state in such a way as to preclude formation of biconcave disks. Crosslinking of proteins with monofunctional aldehydes has been observed previously (27) and, in fact, high concentrations of acetaldehyde have been shown to produce erythrocytes with stiffened membranes $(28,29)$. However, the degree of cross-linking of $\mathrm{HbS}$ by glyceraldehyde (less than $3 \%$ ) and the amount of cross-linking in the membrane would appear to be too small to account for the morphological changes in sickle erythrocytes as well as for the increase in the minimum gelling concentration of deoxyhemoglobin $\mathrm{S}$. Further studies with aldehydes that inhibit sickling but do not lead to cross-linking may help resolve these questions on the mechanism of action of glyceraldehyde.
With respect to the potential application of glyceraldehyde in the treatment of sickle-cell disease, there is already considerable literature on its pharmacology. Thus, the mean lethal dose of DL-glyceraldehyde injected intraperitoneally into mice has been reported to be about $3 \mathrm{~g} / \mathrm{kg}(30,31)$. However, experiments in animals to determine the effect of glyceraldehyde on the circulating erythrocyte are necessary before consideration of any clinical studies.

Comparison of the modes of action of sodium cyanate (20) and of glyceraldehyde in their inhibition of erythrocyte sickling is of interest. Under physiological conditions, the former compound acts principally by shifting the oxygen equilibrium of carbamylated hemoglobin $S$ into the range of hemoglobin $A(2,32,33)$. Glyceraldehyde, on the other hand, directly reduces the polymerization of deoxyhemoglobin $S$. Thus, the action of both compounds is complementary in modulating the aberrant properties of an abnormal gene product, $\mathrm{HbS}$.

\section{ACKNOWLEDGMENTS}

We are grateful to Miss Leanne C. Raney for her expert assistance. We also thank Doctors Charles M. Peterson and John F. Bertles for generous supplies of blood. Elemental analyses were kindly performed by Mr. S. T. Bella. The facilities provided by Doctors Stanford Moore and William $\mathbf{H}$. Stein are appreciated.

This work was supported in part by grants from the $\mathrm{Na}$ tional Institutes of Health (HL-18819 and GM-07256) and from the National Foundation/March of Dimes.

\section{REFERENCES}

1. Nigen, A. M., and J. M. Manning. 1977. Inhibition of erythrocyte sickling in vitro by DL-glyceraldehyde. Proc. Natl. Acad. Sci. U. S. A. 74: 367-371.

2. Nigen, A. M., N. Njikam, C. K. Lee, and J. M. Manning. 1974. Studies on the mechanism of action of cyanate in sickle cell disease. Oxygen affinity and gelling properties of hemoglobin $\mathrm{S}$ carbamylated on specific chains. J. Biol. Chem. 249: 6611-6616.

3. Harkness, J. 1963. A new instrument for the measurement of plasma-viscosity. Lancet. II: 280-281.

4. Dulbecco, R., and M. Vogt. 1954. Plaque formation and isolation of pure lines with poliomyelitis viruses. $J$. Exp. Med. 99: 167-182.

5. Emerson, C. P., Jr., S. C. Shen, T. H. Ham, E. M. Fleming, and W. B. Castle. 1956. Studies on the destruction of red blood cells. IX. Arch. Intern. Med. 97: $1-38$.

6. Weber, K., and M. Osborn. 1969. The reliability of molecular weight determinations by dodecyl sulfatepolyacrylamide gel electrophoresis. J. Biol. Chem. 244: 4406-4412.

7. Fairbanks, G., T. L. Steck, and D. F. H. Wallach. 1971. Electrophoretic analysis of the major polypeptides of the human erythrocyte membrane. Biochemistry. 10: 26062617.

8. Huisman, T. H. J., and A. M. Dozy. 1965. Studies on the heterogeneity of hemoglobin. IX. The use of Tris- 
(hydroxymethyl)amino-methane-HCl buffers in the anion exchange chromatography of hemoglobins. J. Chromatogr. 19: 160-169.

9. Nigen, A. M., C. M. Peterson, P.N. Gillette, and J. M. Manning. 1974. Determination of the blood concentrations of cyanate after intravenous administration to patients with sickle-cell disease. J. Lab. Clin. Med. 83: 139-146.

10. Beutler, E., and E. Guinto. 1974. The reduction of glyceraldehyde by human erythrocytes. L-Hexonate dehydrogenase activity. J. Clin. Invest. 53: 1258-1264.

11. Riddle, V., and F. W. Lorenz. 1968. Nonenzymic, polyvalent anion-catalyzed formation of methylglyoxal as an explanation of its presence in physiological systems. $J$. Biol. Chem. 243: 2718-2724.

12. Bookchin, R. M., and R. L. Nagel. 1971. Ligand-induced conformational dependence of hemoglobin in sickling interactions. J. Mol. Biol. 60: 263-270.

13. Blood and other body fluids. 1961. D. S. Dittmer, editor. Federation of American Societies for Experimental Biology. 200-201.

14. French, D., and J. T. Edsall. 1945. The reactions of formaldehyde with amino acids and proteins. Adv. Protein Chem. II: 277-335.

15. Kant, J. A., and T. L. Steck. 1973. Specificity in the association of glyceraldehyde 3-phosphate dehydrogenase with isolated and human erythrocyte membranes. $J$. Biol. Chem. 248: 8457-8464.

16. Harris, J. W., and R. W. Kellermeyer. 1970. The Red Cell. Harvard University Press, Cambridge, Mass. 193.

17. Harris, J. W., H. H. Brewster, T. H. Ham, and W. B. Castle. 1956. Studies on the destruction of red blood cells. X. Arch Intern. Med. 97: 145-168.

18. Rieber, E. E., G. Veliz, and S. Pollack. 1977. Red cells in sickle cell crisis: Observations on the pathophysiology of crisis. Blood. 49: 967-979.

19. Chien, S., S. Usami, J. Kung-ming, J. Smith, and J. F. Bertles. 1975. Blood rheology in sickle cell disease. In Proceedings of the Symposium on Molecular and Cellular Aspects of Sickle-Cell Disease. J. I. Hercules, G. L. Cottam, M. R. Waterman, and A. N. Schechter, editors. Department of Health, Education, and Welfare Publication 76-1007. 277-303.

20. Cerami, A., and J. M. Manning. 1971. Potassium cyanate as an inhibitor of the sickling of erythrocytes in vitro. Proc. Natl. Acad. Sci. U. S. A. 68: 1180-1183.

21. Benesch, R., R. E. Benesch, and S. Yung. 1974. Chemi- cal modifications that inhibit gelation of sickle hemoglobin. Proc. Natl. Acad. Sci. U. S. A. 71: 1504-1505.

22. Holmquist, W. R., and W. A. Schroeder. 1966. A new $\mathrm{N}$-terminal blocking group involving a Schiff base in hemoglobin $A_{I C}$. Biochemistry. 5: 2489-2503.

23. Bunn, H. F., D. N. Haney, K. H. Gabbay, and P. M. Gallop. 1975. Further identification of the nature and linkage of the carbohydrate in hemoglobin $\mathrm{A}_{\mathrm{IC}}$. Biochem. Biophys. Res. Commun. 67: 103-109.

24. Koenig, R. J., and A. Cerami. 1975. Synthesis of hemoglobin $A_{\mathrm{IC}}$ in normal and diabetic mice: potential model of basement membrane thickening. Proc. Natl. Acad. Sci. U. S. A. 72: 3687-3691.

25. Abdella, P. M., J. M. Ritchey, J. W. O. Tam, and I. M. Klotz. 1977. Glycosylation of hemoglobin $S$ by reducing sugars and its effect on gelation. Biochim. Biophys. Acta. 490: 462-470.

26. van Heyningen, R. 1969. The metabolism of D-glyceraldehyde by the lens. Biochem. J. 112: 211-220.

27. Mohammad, A., H. S. Olcott, and H. Fraenkel-Conrat. 1949. The reaction of proteins with acetaldehyde. Arch. Biochem. Biophys. 24: 270-280.

28. Vassar, P. S., J. M. Hards, D. E. Brooks, B. Hagenberger, and G. V. F. Seaman. 1972. Physicochemical effects of aldehydes on the human erythrocyte. J. Cell Biol. 53: 809-818.

29. Gaines, K. C., J. M. Salhany, D. J. Tuma, and M. F. Sorrell. 1977. Reaction of acetaldehyde with human erythrocyte membrane proteins. FEBS (Fed. Eur. Biochem. Soc.) Lett. 75: 115-119.

30. Eng, C. P., M. K. Bhatnagar, and J. F. Morgan. 1972. Inhibition of mouse ascites tumors by carbohydrate combined with immunization. Can.J. Physiol. Pharmacol. 50: $156-163$.

31. Apple, M. A., F. C. Ludwig, and D. M. Greenberg. 1970. Selective cancer growth inhibition in mice by dihydroxypropanal without concomitant inhibition of bone marrow or other normal tissue. Oncology (Basel). 24: 210-222.

32. de Furia, F. G., D. R. Miller, A. Cerami, and J. M. Manning. 1972. The effects of cyanate in vitro on red blood cell metabolism and function in sickle cell anemia. J. Clin. Invest. 51: 566-574.

33. Jensen, M., H. F. Bunn, G. Halikas, Y. W. Kan, and D. G. Nathan. 1973. Effects of cyanate and 2,3-diphosphoglycerate on sickling. Relationship to oxygenation. J. Clin. Invest. 52: 2542-2547. 